\title{
(C) OPEN ACCESS \\ Using a network organisational architecture to support the development of Learning Healthcare Systems
}

\author{
Maria T Britto, ${ }^{1}$ Sandra C Fuller, ${ }^{1}$ Heather C Kaplan, ${ }^{1,2}$ Uma Kotagal, ${ }^{1}$ \\ Carole Lannon, ${ }^{1,3}$ Peter A Margolis, ${ }^{1}$ Stephen E Muething, ${ }^{1}$ \\ Pamela J Schoettker, ${ }^{1}$ Michael Seid ${ }^{1,4}$
}

${ }^{1}$ James M Anderson Center for Health Systems Excellence, Cincinnati Children's Hospital Medical Center, Cincinnati, Ohio, USA

${ }^{2}$ Perinatal Institute, Cincinnati Children's Hospital Medical Center, Cincinnati, Ohio, USA ${ }^{3}$ Senior Quality Advisor, American Board of Pediatrics, Chapel Hill, NC, USA

${ }^{4}$ Pulmonary Medicine, Cincinnati Children's Hospital Medical Center, Cincinnati, Ohio, USA

\section{Correspondence to}

Pamela J Schoettker, James M Anderson Center for Health Systems Excellence, Cincinnati Children's Hospital Medical Center, Cincinnati, OH 45229, USA;

Pam.Schoettker@cchmc.org

Received 26 July 2017 Revised 22 December 2017 Accepted 27 December 2017 Published Online First

5 February 2018
Check for updates

To cite: Britto MT, Fuller SC, Kaplan HC, et al. BMJ Qual Saf 2018:27:937-946.

\begin{abstract}
The US National Academy of Sciences has called for the development of a Learning Healthcare System in which patients and clinicians work together to choose care, based on best evidence, and to drive discovery as a natural outgrowth of every clinical encounter to ensure innovation, quality and value at the point of care. However, the vision of a Learning Healthcare System has remained largely aspirational. Over the last 13 years, researchers, clinicians and families, with support from our paediatric medical centre, have designed, developed and implemented a network organisational model to achieve the Learning Healthcare System vision. The network framework aligns participants around a common goal of improving health outcomes, transparency of outcome measures and a flexible and adaptive collaborative learning system. Team collaboration is promoted by using standardised processes, protocols and policies, including communication policies, data sharing, privacy protection and regulatory compliance. Learning methods include collaborative quality improvement using a modified Breakthrough Series approach and statistical process control methods. Participants observe their own results and learn from the experience of others. A common repository (a 'commons') is used to share resources that are created by participants. Standardised technology approaches reduce the burden of data entry, facilitate care and result in data useful for research and learning. We describe how this organisational framework has been replicated in four conditions, resulting in substantial improvements in outcomes, at scale across a variety of conditions.
\end{abstract}

The current healthcare system is unreliable, ${ }^{1}$ error prone ${ }^{2}$ and costly. ${ }^{3}$ It fails to meet patient and family needs, and produces unsatisfactory outcomes. ${ }^{4}$ Moreover, the evidence required to provide care that is safe, effective, patient centred, timely, efficient and equitable is often lacking, unfamiliar to providers or inadequately applied. ${ }^{5}$ To address these challenges, the National Academy of Sciences envisioned a
Learning Healthcare System ${ }^{6}$ in which clinical care, science, informatics, incentives and culture are aligned for continuous improvement, innovation and research; new knowledge is captured as a by-product of care, and evidence is applied reliably and is seamlessly embedded in the delivery process. ${ }^{7}$

There have been few published examples of functioning Learning Healthcare Systems. Over the last 13 years, researchers, clinicians and families, with support from our paediatric medical centre and leadership from the American Board of Pediatrics, have designed, developed and implemented networkbased Learning Healthcare Systems that we call Learning Networks to improve the health of populations of children and youth. Our four most mature Learning Networks have achieved substantial improvements in outcomes. ${ }^{8-14}$ Here we describe the common framework and methods of our Learning Networks and how the network model supports the transformation of the healthcare system towards a Learning Healthcare System.

\section{THE ORGANISATIONAL ARCHITECTURE OF LEARNING NETWORKS}

While their size, scope and clinical focus differ (table 1), all Learning Networks use an 'actor-oriented' 15 network organisational architecture. 'Organizational architecture' refers to the way that an organisation arranges itself to coordinate and control activities and to make decisions about distribution of resources and effort. 'Actors' are people, organisations, databases and registries that are part of 
Table 1 Network-based Learning Health Systems

\begin{tabular}{|c|c|c|c|c|c|}
\hline Network name & Purpose & Primary outcome & $\begin{array}{l}\text { Date } \\
\text { founded }\end{array}$ & $\begin{array}{l}\text { Number of } \\
\text { network sites }\end{array}$ & Funding sources \\
\hline $\begin{array}{l}\text { ImproveCareNow Network- } \\
\text { Inflammatory Bowel Disease } \\
\text { improvecarenow.org }\end{array}$ & $\begin{array}{l}\text { Transform the health, } \\
\text { care and costs for all } \\
\text { children and adolescents } \\
\text { with inflammatory bowel } \\
\text { disease by building a } \\
\text { sustainable collaborative } \\
\text { chronic care network. }\end{array}$ & Clinical remission & 2007 & $\begin{array}{l}96 \text { paediatric care } \\
\text { centres }\end{array}$ & $\begin{array}{l}\text { Non-profit organisation. } \\
\text { Funded through } \\
\text { participation fees, } \\
\text { philanthropy, grants and } \\
\text { in-kind contributions }\end{array}$ \\
\hline $\begin{array}{l}\text { Children's Hospitals' Solutions for } \\
\text { Patient Safety (SPS) } \\
\text { www.solutionsforpatientsafety.org }\end{array}$ & $\begin{array}{l}\text { Eliminate serious } \\
\text { harm associated with } \\
\text { healthcare. }\end{array}$ & $\begin{array}{l}\text { Reductions in hospital- } \\
\text { acquired conditions, 7-day } \\
\text { readmissions, serious safety } \\
\text { events, days away restricted } \\
\text { or transferred }\end{array}$ & 2009 & 112 hospitals & $\begin{array}{l}\text { Cardinal Health } \\
\text { Foundation, Children's } \\
\text { Hospital Association, } \\
\text { Federal Partnership for } \\
\text { Patients programme and } \\
\text { participation fees }\end{array}$ \\
\hline $\begin{array}{l}\text { Ohio Perinatal Quality Collaborative } \\
\text { (OPQC) } \\
\text { www.opqc.net }\end{array}$ & $\begin{array}{l}\text { Through collaborative use } \\
\text { of improvement science } \\
\text { methods, reduce preterm } \\
\text { births and improve } \\
\text { perinatal and preterm } \\
\text { newborn outcomes } \\
\text { in Ohio as quickly as } \\
\text { possible. }\end{array}$ & $\begin{array}{l}\text { Prematurity rates, rates of } \\
\text { early elective delivery, length } \\
\text { of stay, length of treatment } \\
\text { for infants with neonatal } \\
\text { abstinence syndrome, late- } \\
\text { onset nosocomial infection }\end{array}$ & 2008 & $\begin{array}{l}105 \text { maternity } \\
\text { hospitals; } 23 \\
\text { outpatient } \\
\text { maternity care } \\
\text { providers; } 52 \\
\text { neonatal units; } 5 \\
\text { federally qualified } \\
\text { health centres }\end{array}$ & $\begin{array}{l}\text { State funding through } \\
\text { Ohio Department } \\
\text { of Health and Ohio } \\
\text { Department of } \\
\text { Medicaid; grants } \\
\text { (Centers for Disease } \\
\text { Control and Prevention) }\end{array}$ \\
\hline $\begin{array}{l}\text { National Pediatric Cardiology Quality } \\
\text { Improvement Collaborative (NPC-QIC) } \\
\text { https://npcqic.org/ }\end{array}$ & $\begin{array}{l}\text { Reduce mortality and } \\
\text { increase quality of life } \\
\text { for infants with single- }\end{array}$ & $\begin{array}{l}\text { Phase 1: interstage survival } \\
\text { and growth rates } \\
\text { Phase 2: improve outcome }\end{array}$ & 2009 & $\begin{array}{l}63 \text { paediatric } \\
\text { cardiology care } \\
\text { centres }\end{array}$ & $\begin{array}{l}\text { Participation fees from } \\
\text { enrolled centres, federal } \\
\text { and private grants }\end{array}$ \\
\hline
\end{tabular}

ventricle congenital heart between diagnosis and first disease. birthday

\begin{tabular}{|c|c|c|c|c|c|}
\hline $\begin{array}{l}\text { Pediatric Rheumatology Care and } \\
\text { Outcomes Improvement Network (PR- } \\
\text { COIN) } \\
\text { https://pr-coin.org/ }\end{array}$ & $\begin{array}{l}\text { Dramatically improve the } \\
\text { outcomes of care for all } \\
\text { children with rheumatic } \\
\text { conditions. }\end{array}$ & $\begin{array}{l}\text { Patients with inactive/low } \\
\text { disease activity score }\end{array}$ & 2010 & $\begin{array}{l}18 \text { paediatric } \\
\text { rheumatology } \\
\text { centres }\end{array}$ & $\begin{array}{l}\text { Anonymous donors, } \\
\text { foundations, } \\
\text { federal grants, } \\
\text { American College of } \\
\text { Rheumatology and } \\
\text { participation fees }\end{array}$ \\
\hline $\begin{array}{l}\text { Autism Speaks—Autism Treatment } \\
\text { Network/Autism Intervention Research } \\
\text { Network on Physical Health } \\
\text { http://airpnetwork.org/what-we-do/ } \\
\text { autism-learning-network }\end{array}$ & $\begin{array}{l}\text { Improve the lives of all } \\
\text { children and families with } \\
\text { autism spectrum disorder } \\
\text { by making a high- } \\
\text { quality, comprehensive } \\
\text { and multidisciplinary } \\
\text { continuum of care } \\
\text { accessible within local } \\
\text { communities. }\end{array}$ & In development & 2015 & $\begin{array}{l}12 \text { academic } \\
\text { medical centres }\end{array}$ & $\begin{array}{l}\text { Health Resources and } \\
\text { Services Administration, } \\
\text { Maternal and Child } \\
\text { Health Bureau, Autism } \\
\text { Speaks }\end{array}$ \\
\hline $\begin{array}{l}\text { CF Care Model of the Future } \\
\text { (web site under construction) }\end{array}$ & $\begin{array}{l}\text { Increase life expectancy } \\
\text { for people with cystic } \\
\text { fibrosis (CF) until normal } \\
\text { life span is reached. }\end{array}$ & $\begin{array}{l}\text { Lung function, nutrition, } \\
\text { quality of life }\end{array}$ & 2015 & $\begin{array}{l}29 \text { cystic fibrosis } \\
\text { clinics }\end{array}$ & $\begin{array}{l}\text { Cystic Fibrosis } \\
\text { Foundation }\end{array}$ \\
\hline $\begin{array}{l}\text { Sickle Treatment and Outcomes Research } \\
\text { in the Midwest (STORM) } \\
\text { http://sicklestorm.org/ }\end{array}$ & $\begin{array}{l}\text { Improve quality of life } \\
\text { and health outcomes for } \\
\text { all Midwesterners with } \\
\text { sickle cell disease. }\end{array}$ & In development & 2014 & $\begin{array}{l}6 \text { haematology } \\
\text { practice-based } \\
\text { teams }\end{array}$ & Federal \\
\hline $\begin{array}{l}\text { Improving Renal Outcomes Collaborative } \\
\text { (IROC) } \\
\text { https://irocnow.org/ }\end{array}$ & $\begin{array}{l}\text { Partner with patients with } \\
\text { kidney disease and their } \\
\text { caregivers to achieve } \\
\text { health, longevity and } \\
\text { quality of life equivalent } \\
\text { to the general population. }\end{array}$ & $\begin{array}{l}\text { Blood pressure control, } \\
\text { decreased rejection }\end{array}$ & 2016 & $\begin{array}{l}23 \text { nephrology } \\
\text { clinics }\end{array}$ & $\begin{array}{l}\text { Participation fees and } \\
\text { donations }\end{array}$ \\
\hline
\end{tabular}

the network. The actor-oriented organisational architecture differs from hierarchical or matrix organisations. It is more flexible and adaptable, allowing more distributed decision-making to enable large groups of people (patients, families, clinicians, researchers, health system leaders) to self-organise to solve problems in the healthcare system that are important to them. ${ }^{15}$ 
The actor-oriented network organisational form has three components: (1) aligning participants around a common goal; (2) standards, processes, policies and infrastructure to enable multiactor collaboration; and (3) a commons where information, knowledge, resources and know-how ${ }^{16}$ to achieve that goal are created and shared. ${ }^{15}$ The model recognises that humans are predisposed to be cooperative and prosocial, ${ }^{17-19}$ and that an appropriately designed organisation can facilitate these predispositions, thereby facilitating cooperation and coproduction, ${ }^{20}$ at scale, to improve health, care and outcomes. ${ }^{21}$ These three elements are further described below using our four most mature networks as examples.

\section{Aligning participants around a common goal}

A central role of network leaders is to facilitate alignment around the common goal of improving the health of a defined population (table 1). Leaders ensure that the mission, vision and values are defined and visible, are understood by participants and are used to align and guide the network's activities.

Network leaders seek to build a sense of shared responsibility and accountability for outcomes and to facilitate learning from performance data. Within the network, there is a high degree of transparency across sites and ongoing sharing, at meetings and webinars, of measures of aggregate and site-level performance, including outcome and process. Data are used to illustrate variation across sites in a way that stimulates curiosity and that promotes learning from those achieving unusually good results. For example, high-performing sites are often invited to teach others how they made improvements. A focus on the use of data for improvement rather than judgement or evaluation, and of sharing what works and what doesn't, promotes trust. ${ }^{8}$ For example, a key premise in the Solutions for Patient Safety (SPS) Network, and a condition of acceptance, is that participating hospitals commit that they will not use safety data for competitive purposes or display it publicly. In addition to undertaking specific projects, such as a central-line infection prevention bundle, all members of SPS must also commit to building a safety culture. Together, these approaches maintain a focus on improving outcomes and encourage participants to observe their own results relative to others, and learn from the experience of others.

Leaders also emphasise that impact will be accelerated through generous sharing of ideas, knowledge and know-how. For example, core messaging in the ImproveCareNow Network is about being part of a larger community, that individual action makes a difference and of being part of the solution. ImproveCareNow's credo-to share seamlessly and steal shamelessly_promotes an 'all teach, all learn' culture of collaboration $^{22}$ to encourage sharing of ideas and care practices.
Each network communicates to stakeholders about the many opportunities for involvement (eg, leadership roles, work groups, quality improvement teams) with the goal of building leadership that is distributed across all levels of each network and of coproduction ${ }^{20}$ of services. For example, the National Pediatric Cardiology Quality Improvement Collaborative (NPC-QIC) has a formal partnership with a national organisation of mothers of children with hypoplastic left heart, called Sisters-byHeart (http://www.sistersbyheart.org/). Parents serve as leaders of work groups and the research committee. As groups of individuals create tools and resources, ongoing network meetings and interactions facilitate peer-to-peer sharing of these materials.

\section{Standards, processes, policies and infrastructure to enable multiactor collaboration}

We have described previously the capabilities required of collaborative improvement networks. ${ }^{23}$ Network infrastructure and processes are organised around six network capabilities: governance and policies, network management, quality improvement, research facilitation, engagement and information technology. The ongoing development across networks of standardised infrastructure reduces start-up and operational costs. Each network customises these elements for their own community.

Examples of network governance processes and policies include: membership policies (guidelines, rights and obligations for members), collaboration and attribution policies (authorship, copyright and intellectual policy), data sharing policies (data access, ownership, privacy, security), research and regulatory policies (informed consent, master reliance agreement) and privacy oversight (regarding patient-generated data). Networks evaluate their policies as part of regular cycles of strategic planning. Stakeholders (patients, families, clinicians, researchers) participate in all aspects of governance at both network and local levels.

Leaders and staff have dedicated time for network management and operations. Mature networks regularly evaluate their management structure and processes as a part of routine operations. Standard operating procedures are used and continuously improved.

Quality improvement methods provide the foundation to promote ongoing learning and adaptation within and across network sites and among participants. Networks use a standard framework for quality improvement (ie, the Model for Improvement ${ }^{24} 25$ ) as well as standardised improvement tools (eg, Key Driver Diagrams, ${ }^{26}$ tools for plan-do-study-act cycles $^{24}$ ). Logic models such as Key Driver Diagrams are used to describe and document theories of change and create awareness among participants of the components of each network system, and how interventions to improve those components work together to achieve the desired goal of the network. ${ }^{26-28}$ Figure 1 shows 


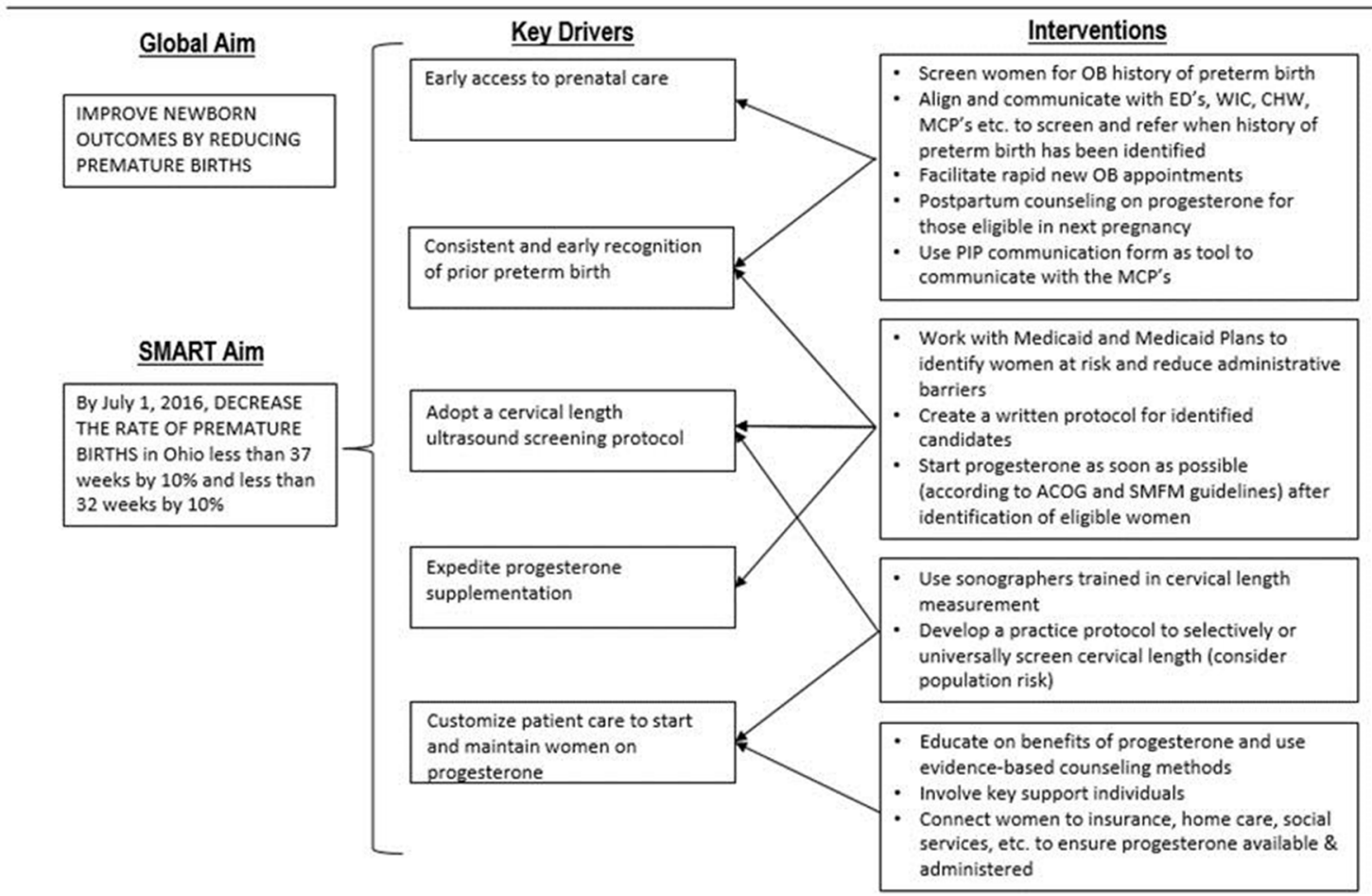

Figure 1 Key Driver Diagram for Ohio Perinatal Quality Collaborative (OPQC). ACOG = American College of Obstetricians and Gynecologists; CHW = community health workers; $\mathrm{ED}=$ emergency departments; $\mathrm{MCP}=$ managed care plans; $\mathrm{OB}$ - obstetric; PIP = progesterone improvement project; $\mathrm{SMFM}=$ Society for Maternal-Fetal Medicine; WIC = Special Supplemental Nutrition Program for Women, Infants, and Children

an example Key Driver Diagram from the Ohio Perinatal Quality Collaborative. It describes the network's theory for decreasing the rate of premature births before 32 weeks' gestation in women with a history of preterm births. ${ }^{29}$ Such diagrams are also used to assess if predictions about what is required to achieve desired outcomes are accurate. Thus, the Key Driver Diagram serves as a framework for learning over time. A second example (figure 2) is the SPS Network Key Driver Diagram for elimination of serious harm through a

\section{Solutions for Patient Safety- 7 Year Key Driver Diagram}

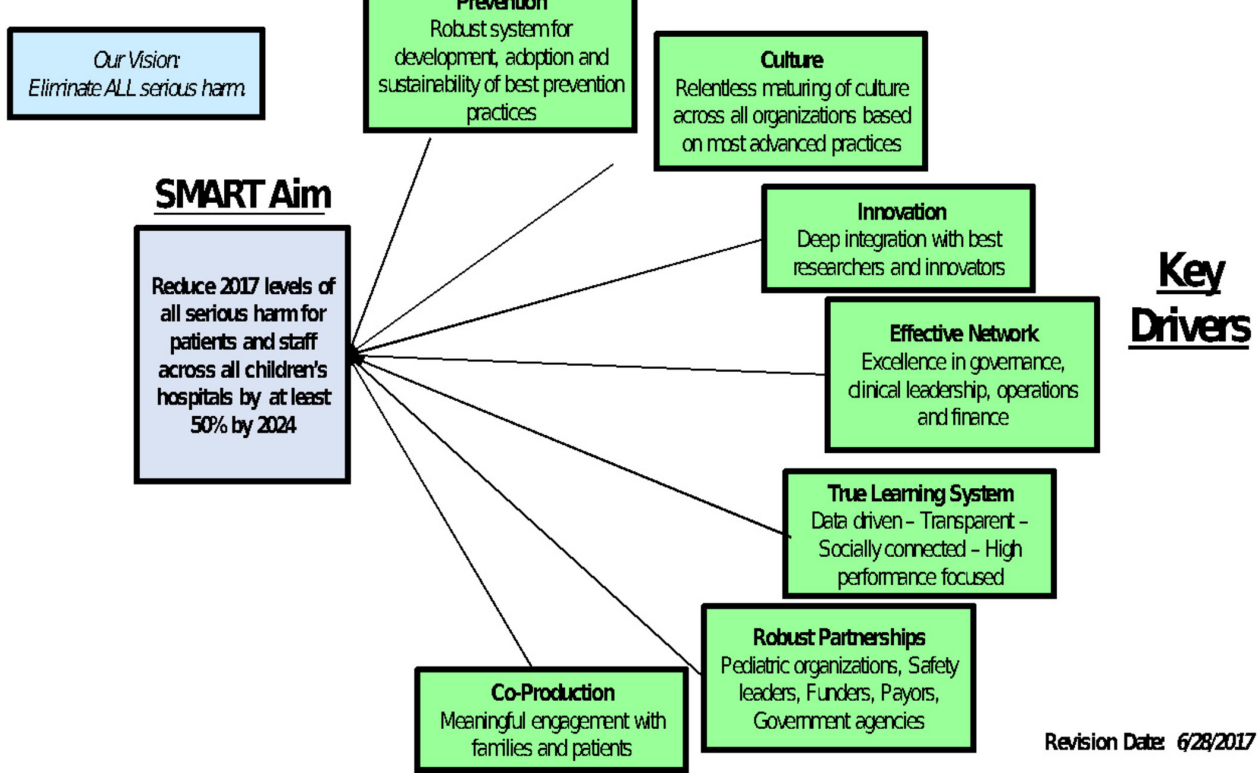

Figure 2 Key Driver Diagram for Children's Hospitals' Solutions for Patient Safety (SPS). 
combination of research and quality improvement. Ongoing analysis of network data uses statistical process control methods to support quality improvement activities. ${ }^{30}$

Networks use a modified Breakthrough Series model $^{3132}$ and elements of the Chronic Care Model. ${ }^{33-37}$ to provide scalable, collaborative, standardised quality improvement training and education and to facilitate peer-to-peer learning. Key principles of the Breakthrough Series model are integrating subject and improvement knowledge to support change, ongoing learning and a structured process of alternating learning sessions and action periods, and peer-to-peer education.

We have adapted the Breakthrough Series model so that it is ongoing, rather than time limited. To accommodate growth, networks transition over time to a 'node' structure in which smaller subnetworks are created. The node structure allows the network to adapt to the needs of participants by organising growth around common contextual characteristics of teams (eg, experience, geography, organisational context). The node structure also facilitates ongoing assessment of participants' improvement capability and the customisation of training to participating sites' needs.

Many Learning Network care centres have adopted registries to facilitate clinical care, improvement and research. The most advanced registry exists for the ImproveCareNow network. ${ }^{38}$ It includes structured data entry fields used by clinicians during the clinical encounter so that data are captured during clinical care. These data are uploaded from the electronic health record system to the registry daily or weekly. The near real-time updating of the registry allows data to be repurposed to support better clinical care, quality improvement, research and advocacy. For example, the ImproveCareNow registry generates previsit planning summaries that make it easier for clinicians to plan visits for patients coming to the clinic and population management reports that segment the entire clinical population, for example, by severity. The utility of up-to-date registry data is further enhanced when supplemented by patient-reported data to drive collaborative tracking. For example, ImproveCareNow is testing an innovation that enables personalised learning using a shared data capture platform that allows patients to work collaboratively with their healthcare providers to identify important issues, track outcomes, understand day-to-day variation in symptoms, learn from n-of- 1 experiments ${ }^{39}$ and facilitate coproduction $^{20}$ of clinical decisions at the individual patient level.

Network registries also facilitate observational research. For example, NPC-QIC's registry, with over 2100 patients with this rare condition, is the largest database of these patients in the world. Registry-informed research led to a care bundle for improving nutrition and growth and the identification of an unexpected medication association with reduced interstage mortality. ${ }^{9-11}$

Several networks have used formal methods for ongoing research prioritisation, involving multistakeholder input, review of existing evidence and analysis of each network's own outcome and process data. There are also training resources for multiple stakeholder groups on how to do research, and support for protocol development to assist research teams with resources such as preparatory-to-research queries and methodological consultation. Mature networks also evaluate the impact of their research resources as part of ongoing, annual planning.

Networks promote engagement and collaboration through widespread communication at the level of network, the care centre and the individual. ${ }^{20} 40$ Time and contributions of all partners are valued, demonstrated and celebrated. There is a distributed training for coproduction, ${ }^{20}$ including the use of a coproduction change package (a set of change concepts, measures and specific tools) to help care centres identify and on-board patients and families to the improvement team. Several networks use community organising methods to promote leadership development at the local and network levels.

\section{A commons to create and share resources to achieve shared goals}

The focus on shared goals and the standard processes noted above result in the creation, accumulating and sharing of resources to achieve these goals. Sharing takes place within and across networks. In addition to pooling data in registries, Learning Networks use a variety of platforms to share other types of resources. One such platform is the Learning Exchange. The Learning Exchange serves as an online community commons. It was purpose built to fit into the Learning Networks' particular culture and ethos. The Exchange was originally designed as similar to Pinterest—as a visually focused web platform offering image-cued discovery, curation and sharing. Individuals 'pin' tools and resources (including documents, images, videos and hyperlinks), can create 'boards' where they collect others' pins, follow others, and mix and reuse others' contributions. The Exchange also supports the work of the Learning Networks: teams can post 90-day and annual goals, find materials for webinars and community conferences and view their monthly reports. High rates of participation-pinning, downloading and commenting-attest to the Exchange's utility as a commons where knowledge is created and shared.

There are several types of shared resources that become available to participants in Learning Networks, such as shared knowledge, shared tools and resources, shared standards and shared situational awareness. Shared situational awareness is 'an up-to-date portrait of problems and opportunities in 


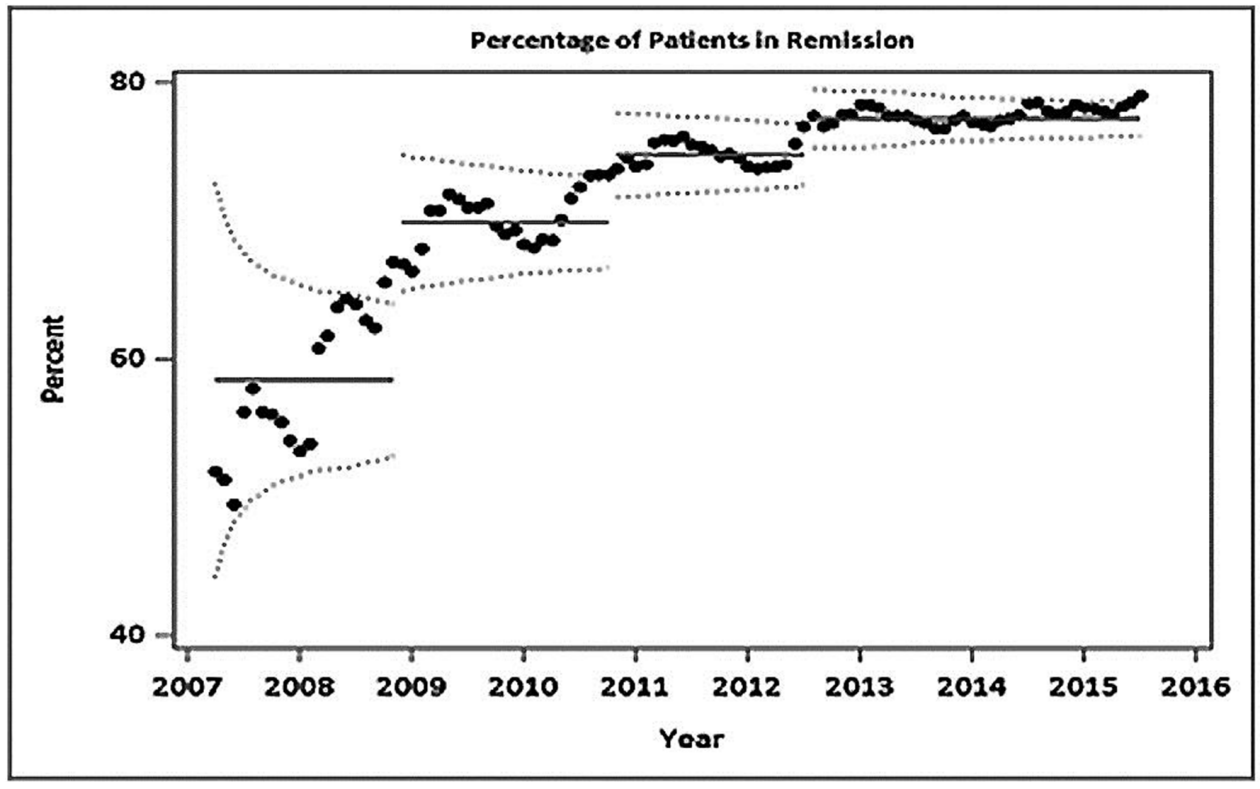

Figure 3 Patients in ImproveCareNow (ICN) with inflammatory bowel disease in remission.

the organization's environment as well as the current availability of resources to address those problems and opportunities. ${ }^{15}$ Learning Network leaders and teams receive monthly reports on network functioning and on processes and outcomes. These are used during monthly calls and network leadership meetings to assess the degree to which the network is functioning as anticipated and achieving goals, and to highlight areas where learning can be harvested, such as which teams are performing well. Teams can post 90-day goals on a shared platform like the Exchange, which allows teams from all care centres to identify others who are interested in working on similar problems.

Another available resource is shared tools. Examples include reports that are created from registry data, such as previsit planning and population management reports, noted above, and worksheets, such as those for flow diagrams, failure modes and effects analysis, ${ }^{41}$ and plan-do-study-act cycles. When teams use these tools, they are expected to share the results back to the commons, which creates a shared knowledge base. Sharing what was learnt allows the surfacing of tacit or contextual knowledge that facilitates uptake of useful innovations. Another resource is shared standards. Clear and available standards, such as a common data model, data transfer standards, measurement standards and control chart standards, represent shared 'how-to' resources.

\section{OUTCOMES}

Sample results from our four most mature Learning Networks are presented in figures 3-6. In ImproveCareNow, improvements in both care processes and outcomes have been sustained, ${ }^{12}{ }^{14}$ with $80 \%$ of the population now in clinical remission (figure 3). In the National Pediatric Cardiology Quality Improvement Collaborative, interstage mortality has been reduced

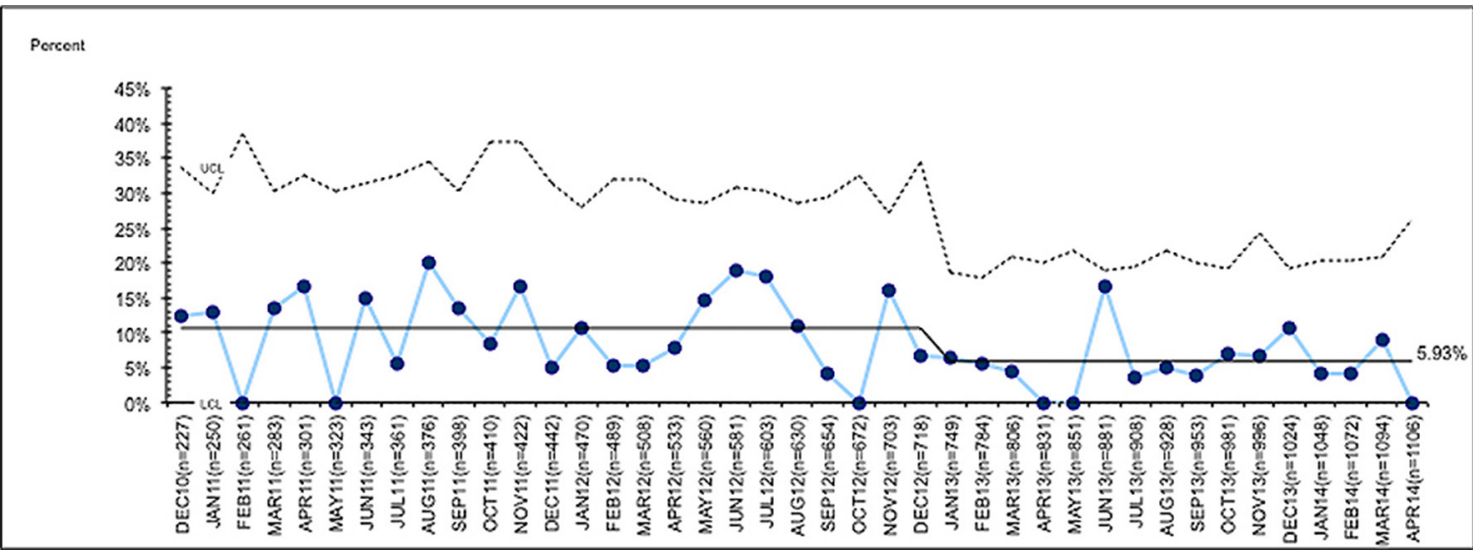

Figure 4 Interstage mortality for infants with single-ventricle congenital heart disease in the National Pediatric Cardiology Quality Improvement Collaborative (NPC-QIC). 
Children'o Mospitals:

Solutions for

Patient Safety
Catheter-Associated

Urinary Tract Infection Rate

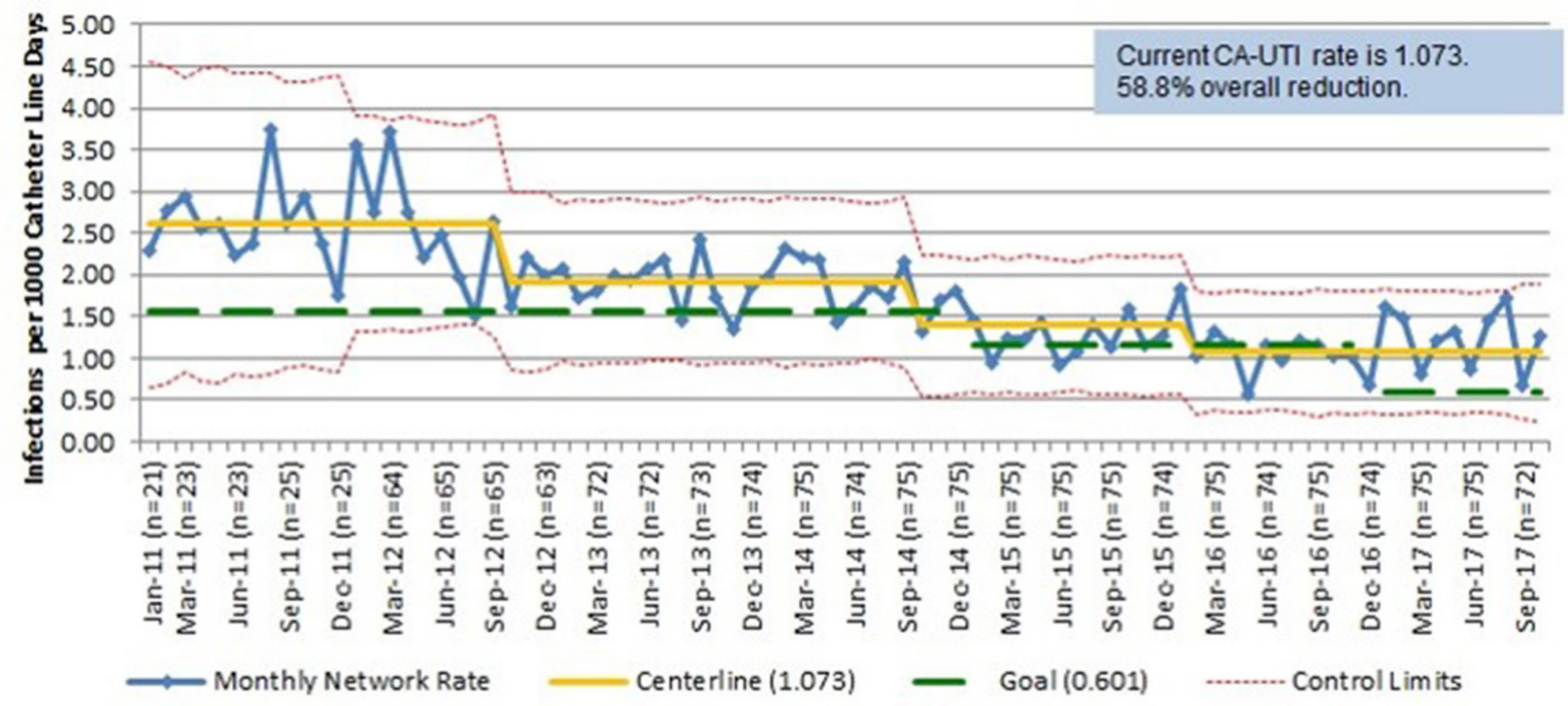

(๑) Copyright 2017, Ohio Children's Hospitals Solutions for Patient Safety (OCHSPS). All rights reserved. This document was created as part of the quality assessment and peer review activities of OCHSPS Learning Network and, the underlying information used to create this document is not subject to discovery pursuant to Ohio Revised Code Section 2305.25, 2305.251, 2305.252, and 2305.253. Any disclosure, copying, distribution or use of this information prohibited without the express permission of OCHSPS.

Figure 5 Catheter-associated urinary tract infections (CA-UTI) for patients in Children's Hospitals' Solutions for Patient Safety (SPS).

by $40 \%$ (figure 4 ), ${ }^{9}$ with a current $95 \%$ survival across the network. Network-level outcomes in these two chronic disease networks improved significantly within $2-3$ years. ${ }^{9-12}$

In the SPS Network, multiple hospital-acquired conditions have been reduced by 5\%-79\% in the last 5 years across participating sites, including a 39\% reduction in adverse drug events, a $46 \%$ reduction in catheter-associated urinary tract infections (figure 5), a $13 \%$ reduction in catheter-associated bloodstream infections, a $32 \%$ reduction in surgical site infections, a $46 \%$ reduction in ventilator-associated pneumonia and a $79 \%$ reduction in injuries from falls. ${ }^{42}$ Ohio Perinatal Quality Improvement Collaborative obstetric and neonatology projects have resulted in many improved outcomes. Scheduled (early elective) deliveries before 39 weeks' gestation that lack a documented medical indication have been reduced

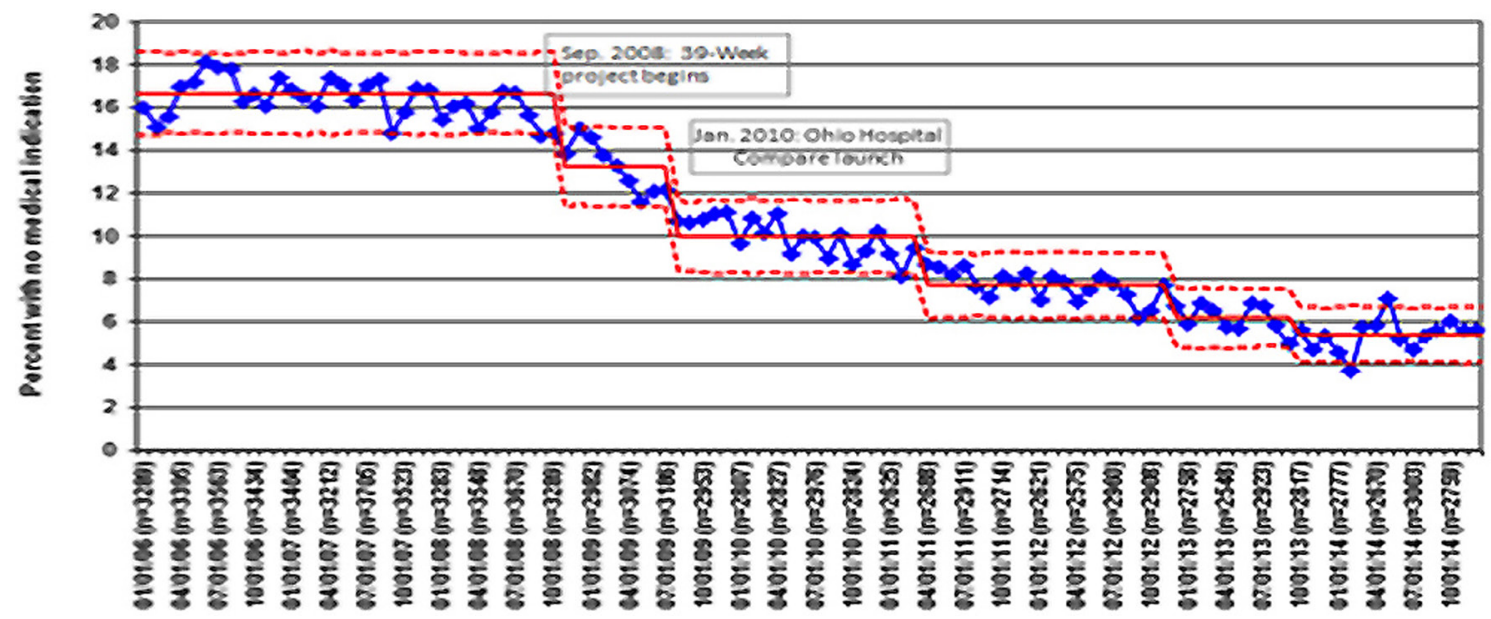

Figure 6 Scheduled (early elective) deliveries before 39 weeks' gestation that lack a documented medical indication for patients in the Ohio Perinatal Quality Collaborative (OPQC). 
$40 \%$ (figure 6). ${ }^{13}$ As a result, over 50000 births have been shifted to term since 2008. Networks have also spawned numerous forms of observational and interventional research, ${ }^{9-1343}$ as well as the development of innovations.

Together, the ability to accelerate improvement in clinical care, innovation and research has produced significant value. For example, improving safety and clinical outcomes may allow care centres to attract more patients. Reducing mortality in hypoplastic left heart results in more clinical revenue. Many teams willingly pay to participate in networks and invest in the staff required to perform well because of the value they derive. For example, the SPS Network estimates that their focus on reliable best practice implementation and a culture of safety improvements have spared $>5000$ children from harm and resulted in estimated savings of $\$ 93$ million to the healthcare system. $^{44}$

\section{DISCUSSION}

We have described Learning Networks, network-based Learning Healthcare Systems that facilitate collaboration and improve health outcomes at scale. Learning Networks share a common framework and methods. These methods have resulted in a replicable process for developing networked Learning Healthcare Systems that produces predictable improvements in outcomes. We have observed improvement in outcomes across multiple diseases and conditions and across participating sites with diverse contexts. While these examples focus on paediatric conditions and issues, the principles should be generalisable to conditions across all of healthcare.

Five key hypotheses have emerged from our work in developing the network organisational model:

1. A focus on improving the outcomes that matter most to patients, families and clinicians results in shared purpose. The relentless focus on outcomes leads to a sense of shared accountability for results.

2. Data transparency, especially about performance on outcomes, is essential. Network leaders play an important role by creating an environment in which transparent sharing of performance data and learning from variation take place. Performance data are used to support improvement, not judgement and criticism. The emphasis on learning builds trust and a culture of solidarity and mastery.

3. Quality improvement methods and the rigorous use of statistical process control facilitate system change by providing structured methods to manage the change process and determine if changes are resulting in improvement. These methods also enable each site to adapt interventions to their own environments and contexts.

4. Networks' infrastructure creates connectivity across participants. Networks create systems and processes that facilitate sharing among actors. Helping each participant share information and resources allows for diverse con- tributions as well as local action. Over time, the social network among and across patients, families, clinicians and scientists grows because each can achieve their most important goals (eg, better health, better care, faster knowledge production). Although networks of patients and caregivers, networks of researchers or networks of clinicians already exist, creating a network by connecting individuals across these traditional boundaries has been foundational to Learning Networks' results.

5. The collaborative infrastructure and standardised policies (eg, Institutional Review Board, data sharing policies), the engaged, networked community, and the rich sources of data that emerge provide great value for research.

Replication by others, as well as detailed studies of the mechanisms by which Learning Networks lead to improved results, will determine whether these hypotheses represent more generalisable knowledge.

\section{CHALLENGES AND LIMITATIONS}

There are numerous barriers to implementing the Learning Healthcare System vision, and collaboration can be difficult and expensive. Clinicians and patients need to learn to engage with each other to coproduce healthcare services and participants need to learn how to share information and use their collective creativity and expertise to solve problems. Data need to be captured, readily available and shared. In addition, leadership and management of a Learning Network require a different style from more centralised organisational models. Unlike traditional healthcare structures, networks invite self-organisation and individualised actions. Leadership takes place through influence. There may be little or no positional authority because the participants come from many different organisations. We are currently developing a graphic representation to help new Learning Networks get established.

The success of a Learning Network depends on problem solving and contribution that emerge as participants become more aware of gaps in performance and how to access ideas needed to close them. Successful individuals and organisations adapt the resources of the network to their own contextual needs. This enables individuals without formal roles to emerge as influential leaders, and unexpected solutions and innovations to emerge. We have observed that it can be difficult for some clinicians to relinquish influence to patients, families and other stakeholders. Since not all solutions are equally useful, processes to assess and test new ideas before they become widespread are valuable.

Establishing a network is expensive and requires significant personnel and technical resources and infrastructure. $^{23}$ Project management, quality improvement, data management and analytical support are key elements of the necessary infrastructure. We are working towards shared platforms for data and communication that can be adapted for use 
by individual networks to decrease the infrastructure needs of each individual network.

The network model that builds on inherent motivation to engage people and contribute differs from traditional business models that achieve competitive advantage through trade secrecy and restricted access to intellectual property. Networks offer tangible incentives such as maintenance of certification credit, continuing education credits and potential for points towards best hospital ranking (eg, US News \& World Report $\left.{ }^{45}\right)$. However, it is the intangible motivation, such as alignment with participants' primary goals (to be healthier, to provide more effective care, to do faster research, to accelerate progress towards organisations' core mission of better outcomes), as well as the ability to learn rapidly from others (eg, patient and family feedback to drive learning among all participants) that seem to facilitate participation. In some areas, such as safety, the participating paediatric community has explicitly been asked not to compete with each other, but rather to learn together. In other areas, competition among centres can be a barrier.

Gaining acceptance within the broader scientific community is a potential barrier to expansion of the Learning Network model. In Learning Networks, multiple changes often occur simultaneously and it is difficult to attribute causality of clinical improvements to a specific intervention. In fact, improvement science has taught us that achieving results often involves multiple strategies, rather than a single 'magic bullet'. This lack of clear causality can be troubling to clinical researchers who are used to more linear causal chains.

\section{CONCLUSION}

Learning Networks integrate data for clinical care, improvement and research to enable patients, caregivers, healthcare providers, researchers and organisations to work together to improve care and health outcomes, spawn innovation and accelerate research. Our network-based Learning Healthcare System model enables alignment of multiple stakeholders around a common goal, making it easier to self-organise into teams to create and share information, knowledge and know-how to achieve that goal. Using a set of standardised processes, the Learning Networks demonstrate a replicable process to improve outcomes across a variety of conditions.

Acknowledgements The authors thank the staff of the James M Anderson Center for Health Systems Excellence at Cincinnati Children's Hospital Medical Center and the patients, families, clinicians and researchers who contribute to all the Learning Networks.

Contributors MTB, PAM and MS participated in the development and implementation of the Learning Networks, helped draft the original manuscript and contributed to its critical revision. SCF, HCK, UK, CL and SEM participated in the development and implementation of the Learning Networks and helped draft the original manuscript. PJS helped draft the original manuscript and contributed to its critical revision.
Funding Sponsor/ funding agency: Patient-Centered Outcomes Research Institute (Grant/contract number: PCS-1406-18643. Title: Anti-TNF monotherapy versus combination therapy with low dose methotrexate in pediatric Crohn's disease); Patient-Centered Outcomes Research Institute (Grant/contract number: PPRND-1507-31321. Title: PCORI PPRN N-of-1 demonstration project); Patient-Centered Outcomes Research Institute (Grant/contract number: CDRN-1306-01556. Title: A national pediatric learning health system); ImproveCareNow (Title: ImproveCareNow Contract-Abbvie-Effectiveness of adalimumab); ImproveCareNow (Title: ImproveCareNow Contract-Celgene-Delayed growth); David R Clare and Margaret C Clare Foundation (Title: Building a collaborative community to improve the health); Agency for Healthcare Research and Quality (Grant/contract number: R18 HS023763. Title: Reduction of nephrotoxic medicationassociated acute kidney injury in children); Patient-Centered Outcomes Research Institute (Grant/contract number: RIPCC-2017. Title: Advancement of PCORnet infrastructure: development of pilot people-centered communities project); Ohio Children's Hospital Solutions for Patient Safety; Cystic Fibrosis Foundation Therapeutics (Grant/contract number: SEID14A0. Title: A C3N for CF: design and development of a peer-produced); Cystic Fibrosis Foundation Therapeutics (Title: A CF C3N care model of the future: proposal for piloting); Agency for Healthcare Research and Quality (Grant/ contract number: R01 HS020024. Title: Building modular pediatric chronic disease registries for QI and CE research); Agency for Healthcare Research and Quality (Grant/contract number: R01HS022974. Title: Enhancing the sustainability of a pediatric learning health system); National Institute of Diabetes and Digestive and Kidney Disease (Grant/contract number: R01DK085719. Title: Open source science: transforming chronic illness care); Agency for Healthcare Research and Quality (Grant/contract number: U19HS021114. Title: Pursuing perfection in pediatric therapeutics).

Competing interests None declared.

Provenance and peer review Not commissioned; externally peer reviewed.

Open access This is an open access article distributed in accordance with the Creative Commons Attribution Non Commercial (CC BY-NC 4.0) license, which permits others to distribute, remix, adapt, build upon this work noncommercially, and license their derivative works on different terms, provided the original work is properly cited and the use is non-commercial. See: http://creativecommons.org/licenses/ by-nc/4.0/

(c) Article author(s) (or their employer(s) unless otherwise stated in the text of the article) 2018. All rights reserved. No commercial use is permitted unless otherwise expressly granted.

\section{REFERENCES}

1 Chassin MR, Loeb JM. High-reliability health care: getting there from here. Milbank Q 2013;91:459-90.

2 Institute of Medicine,. Committee on quality of health care in America. To Err is human: building a safer health system. Washington, D.C: National Academy Press, 1999.

3 Kamal R, Sawyer B. How much is health spending expected to grow? 2017 http://www.healthsystemtracker.org/chartcollection/much-health-spending-expected-grow/\#item-start (accessed 11 July 2017).

4 Gonzales S, Sawyer B. How do mortality rates in the U.S. compare to other countries? 2017. Available at http://www. healthsystemtracker.org/chart-collection/mortality-rates-u-scompare-countries/?_sft_category $=$ health-well-being (accessed 11 July 2017).

5 Olsen L, Aisner D, McGinnis J. The learning healthcare system. Washington, DC: National Academy Press, 2007. 
6 Smith M, Saunders R, Stuckhardt L, et al. Best Care at Lower Cost: The Path to Continuously Learning Health Care America. Washington, DC: National Academies Press, 2013.

7 NAM Leadership Consortium for Value \& Science-Driven Health Care. The Learning Health System Series. Continuous improvement and innovation in health and health care. https:// nam.edu/wp-content/uploads/2015/07/LearningHealthSystem 28jul15.pdf (accessed 6 Dec 2016).

8 Lihn SL, Kugler JD, Peterson LE, et al. Transparency in a Pediatric Quality Improvement Collaborative: A Passionate Journey by NPC-QIC Clinicians and Parents. Congenit Heart Dis 2015;10:572-80.

9 Anderson JB, Beekman RH, Kugler JD, et al. Improvement in Interstage Survival in a National Pediatric Cardiology Learning Network. Circ Cardiovasc Qual Outcomes 2015;8:428-36.

10 Anderson JB, Beekman RH, Kugler JD, et al. Use of a learning network to improve variation in interstage weight gain after the Norwood operation. Congenit Heart Dis 2014;9:512-20.

11 Anderson JB, Iyer SB, Schidlow DN, et al. Variation in growth of infants with a single ventricle. J Pediatr 2012;161:16-21.

12 Crandall WV, Margolis PA, Kappelman MD, et al. Improved outcomes in a quality improvement collaborative for pediatric inflammatory bowel disease. Pediatrics 2012;129:e1030-41.

13 Donovan EF, Lannon C, Bailit J, et al. A statewide initiative to reduce inappropriate scheduled births at 36(0/7)-38(6/7) weeks' gestation. Am J Obstet Gynecol 2010;202:243.e1-8.

14 ImproveCareNow. Purpose \& Success. http://www. improvecarenow.org/purpose-success (accessed 6 Dec 2016).

15 Fjeldstad O, Snow C, Miles R, et al. The architecture of collaboration. Strat Mgmt J 2012;33:734-50.

16 Benkler Y. The wealth of networks: how social production transforms markets and freedom. New Haven, CT: Yale University Press, 2006.

17 Benkler Y. The Penguin and the Leviathan: how cooperation triumphs over self-interest. New York: Crown Business, 2011.

18 Nowak MA. Five rules for the evolution of cooperation. Science 2006;314:1560-3.

19 Wilson D. does altruism exist?: culture, genes, and the welfare of others (foundational questions in science): Yale University Press, 2015.

20 Batalden M, Batalden P, Margolis P, et al. Coproduction of healthcare service. BMJ Qual Saf 2016;25:509-17.

21 Margolis PA, Peterson LE, Seid M. Collaborative Chronic Care Networks (C3Ns) to transform chronic illness care. Pediatrics 2013;131(Suppl 4):S219-23.

22 Nembhard IM. All teach, all learn, all improve?: the role of interorganizational learning in quality improvement collaboratives. Health Care Manage Rev 2012;37:154-64.

23 Lannon CM, Peterson LE. Pediatric collaborative improvement networks: background and overview. Pediatrics 2013;131(Suppl 4):S189-95.

24 Langley G, Nolan K, Nolan T, et al. The improvement guide. a practical approach to enhancing organizational performance. San Francisco: Jossey-Bass, 1996.

25 Moen R, Nolan T, Provost L. Quality improvement through planned experimentation. 2nd ed. New York: McGraw-Hill, 1999.

26 Knowlton L, Phillips C. The logic model guidebook. Better strategies for great results. 2nd ed. Thousand Oaks, CA: Sage, 2013.
27 Reed JE, McNicholas C, Woodcock T, et al. Designing quality improvement initiatives: the action effect method, a structured approach to identifying and articulating programme theory. BMJ Qual Saf 2014;23:1040-8.

28 Goldman D. How Do You Use a Driver Diagram? http://www. ihi.org/education/IHIOpenSchool/resources/Pages/Activities/ GoldmannDriver.aspx (accessed 3 May 2017).

29 Iams JD, Applegate MS, Marcotte MP, et al. A statewide progestogen promotion program in Ohio. Obstet Gynecol 2017;129:337-46.

30 Benneyan JC, Lloyd RC, Plsek PE. Statistical process control as a tool for research and healthcare improvement. Qual Saf Health Care 2003;12:458-64.

31 Institute for Healthcare Improvement. The Breakthrough Series: IHI's Collaborative Model for Achieving Breakthrough Improvement. IHI Innovation Series white paper. Cambridge, MA: Institute for Healthcare Improvement, 2003.

32 Kilo CM. A framework for collaborative improvement: lessons from the Institute for Healthcare Improvement's Breakthrough Series. Qual Manag Health Care 1998;6:1-13.

33 Bodenheimer T, Wagner EH, Grumbach K. Improving primary care for patients with chronic illness. JAMA 2002;288:1775-9.

34 Bodenheimer T, Wagner EH, Grumbach K. Improving primary care for patients with chronic illness: the chronic care model, Part 2. JAMA 2002;288:1909-14.

35 Wagner EH. Chronic disease management: what will it take to improve care for chronic illness? Eff Clin Pract 1998;1:2-4.

36 Wagner EH, Austin BT, Davis C, et al. Improving chronic illness care: translating evidence into action. Health Aff 2001;20:64-78.

37 Wagner EH, Austin BT, Von Korff M. Organizing care for patients with chronic illness. Milbank Q 1996;74:511-54.

38 Marsolo K. In search of a data-in-once, electronic health record-linked, multicenter registry-how far we have come and how far we still have to go. EGEMS 2013;1:3.

39 Kaplan H, Adler J, Saeed S, et al. A personalized learning system for improving patient-physician collaboration. 2013 https://hbr.org/2013/10/a-personalized-learning-system-forimproving-patient-physician-collaboration (accessed 25 Jan 2017).

40 Seid M, Dellal G, Peterson L, et al. Methods for co-designing a collaborative chronic care network (C3N). JMIR Hum Factors. In Press. 2018.

41 Institute for Healthcare Improvement. Failure Modes and Effects Analysis (FMEA) Tool. 2004 http://www.ihi.org/ resources/Pages/Tools/FailureModesandEffectsAnalysisTool. aspx (accessed 10 Feb 2017).

42 Lyren A, Brilli RJ, Zieker K, et al. Children's Hospitals' Solutions for Patient Safety Collaborative Impact on HospitalAcquired Harm. Pediatrics 2017;140:e20163494.

43 Lyren A, Brilli R, Bird M, et al. Ohio children's hospitals' solutions for patient safety: a framework for pediatric patient safety improvement. J Healthc Qual 2016;38:213-22.

44 Lyren A, Brilli RJ, Zieker K, et al. Children's hospitals' solutions for patient safety collaborative impact on hospitalacquired harm. Pediatrics 2017;140:e20163494.

45 U.S. News \& World Report. Rankings \& advice, hospitals, best children's hospital national rankings. http://health. usnews.com/best-hospitals/pediatric-rankings (accessed 15 Sep 2017). 